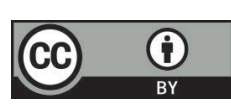

\title{
Effects of comorbidities on COVID-19
}

Chithramali Hasanthika Rodrigo ${ }^{1}$, Bhumini Karunarathna ${ }^{1}$, Dharshini Kantharuban', Indumini Gunatilake $^{3}$, Maheeka Seneviwickrama ${ }^{4}$, Sampatha Goonewardena ${ }^{4}$, Pushpa Jayawardana ${ }^{5}$ Ishanka Ayeshwari Talagala ${ }^{1^{*}}$

${ }^{1}$ Ministry of Health, Sri Lanka; ${ }^{2}$ Provincial Director of Health Services office- Eastern Province, Trincomalee, Sri Lanka; ${ }^{3}$ Postgraduate Institute of Medicine, University of Colombo, Sri Lanka; ${ }^{4}$ Department of Community Medicine, Faculty of Medical Sciences, University of Jayewardenepura, Sri Lanka; ${ }^{5}$ No affiliation

*Correspondence: drishankancd@gmail.com https://orcid.org/0000-0001-6351-2079

DOI: https://doi.org/10.4038/jccpsl.v26i5.8353

Received on 18 May 2020

Accepted on 25 May 2020

\section{Highlights}

- Non-communicable diseases such as diabetes, hypertension, cardiovascular diseases and cancer result in higher risk of COVID-19 infection and severe disease.

- Chronic respiratory diseases may have a protective effect against coronavirus disease.

- Among the gastro-intestinal comorbidities, inflammatory bowel disease and Hepatitis B infection result in severe COVID-19.

\section{Background}

COVID-19 is a pandemic which has affected people across the globe (1). The majority recover on their own and do not need hospitalized treatment (2). However, a substantial proportion $(24.3 \%)$ of the infected patients may become seriously ill resulting in a mortality rate of $6.4 \%$ (3). Furthermore, old aged people and those who have underlying medical conditions such as cardiovascular disease (CVD) and other non-communicable diseases (NCD) and metabolic diseases are at a higher risk of developing serious illness and complications related to COVID$19(2,4)$. Similar presentations had been seen with past coronaviruses as well, where diabetes (11\%) and CVD (8\%) were prevalent with severe acute respiratory syndrome (SARS), and diabetes (50\%), hypertension $(50 \%)$ and CVD $(30 \%)$ with Middle East respiratory syndrome (MERS), resulting in negative outcomes (5).

\section{Hypertension, diabetes and COVID-19}

A systematic review has revealed that the most prevalent comorbidities among COVID-19 infected Chinese patients were hypertension $(21.1 \%$; $95 \%$ $\mathrm{CI}=13.0,27.2 \%)$ and diabetes $(9.7 \% ; 95 \% \mathrm{CI}=7.2$, $12.2 \%$ ) (6). Similar results were obtained in another 
study, where $16.9 \%$ and $8.2 \%$ of the COVID-19 infected patients had hypertension and diabetes, respectively (7). In addition, a study conducted in Wuhan, China ( $\mathrm{n}=138)$ had shown that $31 \%$ suffered from hypertension and 58\% of them required intensive care unit (ICU) care; and of the 10\% suffering from diabetes, $22 \%$ of them needed ICU care, as it resulted in severe COVID-19 disease (8). Guan et al. (2020) (9) revealed similar results in a study among 1099 laboratory-confirmed cases of COVID-19 as well. It is known that the pathogenic coronaviruses bind to the target cells through angiotensin-converting enzyme 2 (ACE2) that is available in the epithelial cells of the kidney, lung, intestines, blood vessels and heart of humans $(5,10)$. It is believed that treatment with ACE inhibitors and angiotensin receptor blockers results in an overexpression of ACE2 among patients with diabetes and hypertension, facilitating the coronavirus infection and severe COVID-19 $(8,10-$ 11). However, there is no sufficient evidence to prove this hypothesis (12).

\section{Cardiovascular diseases and COVID-19}

Cardiovascular disease was found to be another common comorbidity (8.4\%; 95\% CI: 3.8-13.8\%) among the COVID-19 patients (6-7). It is also evident that patients suffering from CVD had more severe disease and negative outcomes of COVID-19 (5-8). In addition, several studies have shown myocardial injury associated with COVID-19. Aforementioned single center study among 138 hospitalized patients with COVID-19 in Wuhan, China reported that elevated cardiac biomarkers such as Troponin I, new ECG abnormalities and echocardiographic abnormalities were present among $7.2 \%$ of the patients; and among them, 22\% required ICU care (8). COVID-19 infection aggravates the damage to the heart further (13). There is also evidence of a vicious cycle, where patients suffering from underlying cardiovascular metabolic diseases have a greater risk of developing severe stages of COVID19 , affecting the prognosis of the disease. Although the exact pathophysiology is yet unknown, elevated levels of ACE2, ACE2 mediated direct myocardial involvement, impaired immune system functions resulting in a cytokine storm, cardiac myocyte apoptosis following hypoxia induced excessive intracellular calcium and older age are believed to predispose those with CVD to COVID-19 and associated severe disease $(5,14-15)$.

\section{Chronic respiratory diseases and COVID-19}

Contrary to the belief that patients with chronic respiratory diseases such as asthma and chronic obstructive pulmonary disease (COPD) would be more vulnerable to coronavirus infection and severe COVID-19 with negative outcomes, the reported prevalence of asthma and COPD have been lower than that of other NCDs such as hypertension, diabetes and CVD (16). According to Halpin et al. (2020) (16), the potential explanation to this scenario could be explained using several mechanisms: 1 . not being diagnosed or poor reporting of the chronic respiratory diseases in contrast to other chronic diseases among patients with COVID-19, 2. the patient with chronic respiratory disease is protected from COVID-19 due to a diverse immune response produced by the underlying respiratory disease and 3 . risk of symptomatic coronavirus infection and severe disease is reduced by their treatment for the underlying respiratory disease.

\section{Gastro-intestinal comorbidities and COVID-19}

Although COVID-19 may affect the management of patients with pre-existing digestive diseases, the impact of the spectrum of digestive conditions on the treatment and outcome of COVID-19 is yet to be understood. However, patients with inflammatory bowel disease (IBD) who are elderly, malnourished, on immunosuppressants, with underlying chronic diseases or pregnant are reported to be potentially at a higher risk of being infected with coronavirus (17). It is evident that severe COVID-19 causes liver injury and was common among those who had Hepatitis B infection $(9,14)$.

\section{Cancers and COVID-19}

A national analysis in China among 1590 laboratoryconfirmed cases of COVID-19 found that $1 \%$ (95\% $\mathrm{CI}=0.61,1.65)$ of the cases had a history of cancer, with lung cancer being the commonest type (28\%) 
(18). It is also reported that COVID-19 patients with cancer had a higher risk of severe disease and negative outcomes (39\% versus 8\%; Fisher's exact $\mathrm{p}=0.0003$ ) and that they deteriorate more rapidly (median time to severe events 13 days (IQR: 6-15) versus 43 days (20-not reached); $\mathrm{p}<0.0001$; hazard ratio 3.56; $95 \% \mathrm{CI}=1.65,7.69$ after adjusting for age) compared to those without cancer. Further, it is shown that patients with a recent history (previous month) of chemotherapy or surgery (75\%) had a higher risk of severe COVID-19 compared to others $(43 \%)$ (adjusted odds ratio $(\mathrm{aOR})=5.34 ; 95 \%$ $\mathrm{CI}=1.80,16.18$ adjusted for age, smoking history and other comorbidities). These findings suggest the requirement of more intense attention to cancer patients with COVID-19 including postponement of treatment for stable cancer (18).

With this background, it is coherent that the presence of comorbidities has a considerable impact on the disease burden of COVID-19 infection.

\section{Public health implications}

It is predicted that COVID-19 infection will last for another two years affecting people across the globe (19). Further, there is a rapid rise in the worldwide prevalence of NCDs as well (20). In this background, where it is evident that the presence of comorbidities increases the risk of coronavirus infection and results in severe COVID-19, stringent measures are called for at all levels of prevention (6).

Therefore, as a primary prevention measure, it is essential that people lead a healthy lifestyle including consumption of a healthy diet, being physically active, smoking cessation and abstinence of alcohol use. A healthy lifestyle among apparently healthy people as well as in those who are already diagnosed with NCDs will boost the immunity to fight against the coronavirus infection and thereby prevent severe disease. On the other hand, it is essential that patients with NCD take extra measures to protect themselves from being infected with coronavirus.

Knowledge on the association of comorbidities with COVID-19 is essential especially to the healthcare staff, so that more intense attention will be given to these patients, as they may present with atypical symptoms, severe underlying comorbidity and may even mask the symptoms of COVID-19 due to medications that they are on. Furthermore, proper clinical evaluation, staging and management of the underlying comorbidity and attention to the possibility of quick deterioration are of utmost importance in the clinical management to prevent further complications and negative outcomes from COVID-19(21).

\section{Gaps in knowledge}

While commending on the various activities that have been implemented to prevent and control of COVID-19 in the country, it is important to note that published data related to comorbidities and COVID19 is minimal in Sri Lanka.

With this evidence on major effects of comorbidities on COVID-19, it is recommended that patients with chronic diseases be advised to control their disease to prevent complications and coronavirus infection. Public health officials, policy planners and implementers should educate and promote the community to lead a healthy lifestyle to prevent and control comorbidities and to prevent coronavirus infection and severe disease. Paying intense attention to atypical presentation, disease progression and rapid deterioration of COVID-19 patients with comorbidities is recommended to prevent negative outcomes.

\section{Author Declaration}

Author contributions: CHR, BK and IAT have made substantial contributions to the conception, drafting and critical analysis for the intellectual content of the manuscript. All authors agreed to be accountable for all aspects of the work in ensuring that questions related to the accuracy or integrity of any part of the work are appropriately investigated and resolved. All authors have read and approved the manuscript.

\section{References}

1. World Health Organization. WHO TimelineCOVID-19. 2020. Available from: https:// 
www.who.int/news-room/detail/27-04-2020who-timeline---covid-19. Accessed 2 May 2020.

2. World Health Organization. $Q \& A$ on coronaviruses (COVID-19) 2020. Available from: https://www.who.int/news-room/q-a-detail/q-acoronavirusesAccessed 2 May 2020.

3. Sun P, Qie S, Liu Z, Ren J, Xi J. Clinical characteristics of 5732 patients with 2019-nCoV infection. (2/16/2020). Available at SSRN: https://ssrn.com/abstract=3539664.

4. Centres for Disease Prevention and Control (CDC). Symptoms of Coronavirus 2020. Available from: https://www.cdc.gov /corona virus/2019ncov/symptoms-testing symptoms.html. Accessed 28 April 2020

5. Clerkin KJ, Fried JA, Raikhelkar J, Sayer G, Griffin JM, Masoumi A. et al., Disease Coronavirus (COVID-19) and cardiovascular disease. Circulation 2019; 141: (20); 1648-1655. DOI: 10.1161/CIRCULATIONAHA.120.046941.

6. Yang J, Zheng Y, Gou X, Pu K, Chen Z, Guo Q, Ji R, Wang H, Wang Y, Zhou Y. Prevalence of comorbidities in the novel Wuhan coronavirus (COVID-19) infection: a systematic review and meta-analysis. International Journal of Infectious Diseases. International Journal of Infectious Diseases 2020; 94: 91-95. DOI: 10.1016 /j.ijid.2020.03.017.

7. Guan WJ, Liang WH, Zhao Y, Liang HR, Chen ZS, Li YM, Liu XQ, Chen RC, Tang CL, Wang T, Ou CQ. Comorbidity and its impact on 1590 patients with Covid-19 in China: A Nationwide Analysis. European Respiratory Journal 2020; 55(5): 2000547. DOI: 10.1183/13993003.00547-2020.

8. Wang D, Hu B, Hu C, Zhu F, Liu X, Zhang J, Wang B, Xiang H, Cheng Z, Xiong Y, Zhao Y. Clinical characteristics of 138 hospitalized patients with 2019 novel coronavirus- infected pneumonia in Wuhan, China. JAMA 2020; 323(11): 1061-1069. DOI: 10.1001/jama.2020. 1585.

9. Guan WJ, Ni ZY, Hu Y, Liang WH, Ou CQ, He JX, Liu L, Shan H, Lei CL, Hui DS, Du B. Clinical characteristics of coronavirus disease 2019 in China. New England Journal of Medicine 2020; 382(18): 1708-1720. DOI: 10.1056/NEJMoa 2002032.

10. Wan Y, Shang J, Graham R, Baric RS, Li F. Receptor recognition by the novel coronavirus from Wuhan: an analysis based on decade-long structural studies of SARS coronavirus. Journal of Virology 2020; 94(7): e00127-20. DOI: 10.1128/JVI.00127-20.

11. Fang L, Karakiulakis G, Roth M. Are patients with hypertension and diabetes mellitus at increased risk for COVID-19 infection? [Published correction appears in Lancet Respiratory Medicine 2020; 8(6): e54. DOI: 10.1016/S22132600(20)30116-8.

12. Schiffrin EL, Flack JM, Ito S, Muntner P, Webb RC. Hypertension and COVID-19, American Journal of Hypertension 2020; 33(5): 373-374. DOI: 10.1093/ajh/hpaa057.

13. Li B, Yang J, Zhao F, Zhi L, Wang X, Liu L, Bi Z, Zhao Y. Prevalence and impact of cardiovascular metabolic diseases on COVID-19 in China. Clinical Research in Cardiology 2020; 109(5): 531-538. DOI: 10.1007/s00392-020-01626-9.

14. Huang C, Wang Y, Li X, Ren L, Zhao J, Hu Y, Zhang L, Fan G, Xu J, Gu X, Cheng Z. Clinical features of patients infected with 2019 novel coronavirus in Wuhan, China. The Lancet 2020; 395(10223): 497-506. DOI: 10.1016/S01406736(20)30183-5.

15. Zheng YY, Ma YT, Zhang JY, Xie X. COVID-19 and the cardiovascular system. Nature Reviews Cardiology 2020; 17(5): 259-260. DOI: 10.1038/s41569-020-0360-5.

16. Halpin DM, Faner R, Sibila O, Badia JR, Agusti A. Do chronic respiratory diseases or their treatment affect the risk of SARS-CoV-2 infection? Lancet Respiratory Medicine 2020; 8(5): 436-438. DOI: 10.1016/S2213-2600(20)30167-3.

17. Mao R, Liang J, Shen J, et al. Implications of COVID-19 for patients with pre-existing digestive diseases [published correction appears in Lancet Gastroenterol Hepatol 2020; 5(7): e6. Lancet Gastroenterology \& Hepatology 2020; 5(5): 425427. DOI: $10.1016 / \mathrm{S} 2468-1253(20) 30076-5$.

18. Liang W, Guan W, Chen R, Wang W, Li J, Xu K, Li C, Ai Q, Lu W, Liang H, Li S. Cancer patients in SARS-CoV-2 infection: a nationwide analysis in China. Lancet Oncology 2020; 21(3): 335-337. DOI: 10. 1016/S1470-2045(20)30096-6.

19. Taylor, C. Coronavirus outbreak likely to go on for two years, scientists predict. CNBC-Health and Science. 2020. Available from: https:// www. 
cnbc.com/2020/05/01/coronavirus-pandemiclikely-to-last-for-two-years-scientists-predict. html. Accessed 3 May 2020.

20. World Health Organization. Non-communicable diseases 2020. Available from: https://www. who.int/news-room/fact sheets/detail/ non communicable-diseases. Accessed 2 May 2020.

21. Wang T, Du Z, Zhu F, Cao Z, An Y, Gao Y, Jiang B. Comorbidities and multi-organ injuries in the treatment of COVID-19. Lancet 2020; 395(10228): e52. DOI: 10. 1016/S01406736(20)30558-4. 